Article type : Original Article

25 October 2017

\title{
Cerebrovascular Events in Systemic Lupus Erythematosus
}

Results from an international, inception cohort study

John G. Hanly $\mathrm{MD}^{1}$, Qiuju Li $\mathrm{PhD}^{2}$, Li Su $\mathrm{PhD}^{2}$, Murray B. Urowitz $\mathrm{MD}^{3}$, Caroline Gordon $\mathrm{MD}^{4}$, Sang-Cheol Bae MD $\mathrm{PhD}^{5}$, Juanita Romero-Diaz MD MSc ${ }^{6}$, Jorge Sanchez-Guerrero MD MSc${ }^{3}$, Sasha Bernatsky MD $\mathrm{PhD}^{7}$, Ann E. Clarke MD MSc${ }^{8}$, Daniel J Wallace $\mathrm{MD}^{9}$, David A. Isenberg MD ${ }^{10}$, Anisur Rahman MD $\mathrm{PhD}^{10}$, Joan $\mathrm{T}$. Merrill $M D^{11}$, Paul Fortin MD MPH ${ }^{12}$, Dafna D. Gladman $M^{3}$, lan N. Bruce $M^{13}$, Michelle Petri $\mathrm{MD}^{14}$, Ellen M. Ginzler MD MPH${ }^{15}$, M.A. Dooley MD MPH ${ }^{16}$, Kristjan Steinsson $\mathrm{MD}^{17}$, Rosalind Ramsey-Goldman MD DrPH${ }^{18}$, Asad A. Zoma MD ${ }^{19}$, Susan Manzi MD MPH ${ }^{20}$, Ola Nived MD $\mathrm{PhD}^{21}$, Andreas Jonsen MD $\mathrm{PhD}^{21}$, Munther $\mathrm{A}$. Khamashta $\mathrm{MD}^{22}$, Graciela S. Alarcón MD $\mathrm{PhD}^{23}$, Winn Chatham $\mathrm{MD}^{23}$, Ronald F. van Vollenhoven $\mathrm{MD}^{24}$, Cynthia Aranow $\mathrm{MD}^{25}$, Meggan Mackay $\mathrm{MD}^{25}$, Guillermo RuizIrastorza $\mathrm{MD}^{26}$, Manuel Ramos-Casals $\mathrm{MD}^{27}$, S. Sam Lim MD MPH${ }^{28}$, Murat Inanc $M D^{29}$, Kenneth C. Kalunian MD ${ }^{30}$, Soren Jacobsen MD DMSc ${ }^{31}$, Christine A. Peschken This article has been accepted for publication and undergone full peer review but has not been through the copyediting, typesetting, pagination and proofreading process, which may lead to differences between this version and the Version of Record. Please cite this article as doi: 10.1002/acr.23509

This article is protected by copyright. All rights reserved. 
$\mathrm{MD}^{32}$, Diane L. Kamen $\mathrm{MD}^{33}$, Anca Askanase MD MPH${ }^{34}$, Chris Theriault $\mathrm{MSc}^{35}$, Vernon Farewell $\mathrm{PhD}^{2}$

\section{Institutions:}

${ }^{1}$ Division of Rheumatology, Department of Medicine and Department of Pathology, Queen Elizabeth II Health Sciences Centre and Dalhousie University, Halifax, Nova Scotia, Canada;

${ }^{2}$ MRC Biostatistics Unit, Institute of Public Health, University of Cambridge, Cambridge, UK;

${ }^{3}$ Centre for Prognosis Studies in the Rheumatic Diseases, Toronto Western Hospital and University of Toronto, ON, Canada;

${ }^{4}$ Rheumatology Research Group, School of Immunity and Infection, College of Medical and Dental Sciences, University of Birmingham, Birmingham, UK;

${ }^{5}$ Department of Rheumatology, Hanyang University Hospital for Rheumatic Diseases, Seoul, Korea;

${ }^{6}$ Instituto Nacional de Ciencias Medicas y Nutrición, Mexico City, Mexico;

${ }^{7}$ Division of Rheumatology, Department of Medicine, McGill University, Montreal, Quebec, Canada;

${ }^{8}$ Division of Rheumatology, Cumming School of Medicine, University of Calgary, Alberta, Canada;

${ }^{9}$ Cedars-Sinai/David Geffen School of Medicine at UCLA, Los Angeles, CA, USA;

This article is protected by copyright. All rights reserved. 
${ }^{10}$ Centre for Rheumatology, Department of Medicine, University College London, UK;

${ }^{11}$ Department of Clinical Pharmacology, Oklahoma Medical Research Foundation, Oklahoma City, OK, USA;

${ }^{12}$ Division of Rheumatology, Centre Hospitalier Universitaire de Québec et Université Laval, Quebec City, Canada;

${ }^{13}$ Arthritis Research UK Epidemiology Unit, Institute of Inflammation and Repair, Manchester Academic Health Sciences Centre, The University of Manchester, Manchester, UK; and NIHR Manchester Musculoskeletal Biomedical Research Unit, Central Manchester University Hospitals NHS Foundation Trust, Manchester Academic Health Science Centre;

${ }^{14}$ Division of Rheumatology, Johns Hopkins University School of Medicine, Baltimore, MD, USA;

${ }^{15}$ Department of Medicine, SUNY Downstate Medical Center, Brooklyn, NY, USA;

${ }^{16}$ Thurston Arthritis Research Center, University of North Carolina, Chapel Hill, NC, USA;

${ }^{17}$ Center for Rheumatology Research, Landspitali University hospital, Reykjavik, Iceland;

${ }^{18}$ Northwestern University and Feinberg School of Medicine, Chicago, IL, USA;

${ }^{19}$ Lanarkshire Centre for Rheumatology, Hairmyres Hospital, East Kilbride, Scotland UK;

${ }^{20}$ Lupus Center of Excellence, Allegheny Health Network, Pittsburgh, PA, USA;

This article is protected by copyright. All rights reserved. 
${ }^{21}$ Department of Clinical Sciences Lund, Rheumatology, Lund University, Lund, Sweden.

${ }^{22}$ Lupus Research Unit, The Rayne Institute, St Thomas' Hospital, King's College London School of Medicine, UK, London, UK;

${ }^{23}$ Department of Medicine, University of Alabama at Birmingham, Birmingham, AL, USA;

${ }^{24}$ Unit for clinical therapy research (ClinTRID), Karolinska Institute, Stockholm, Sweden;

${ }^{25}$ Feinstein Institute for Medical Research, Manhasset, NY, USA;

${ }^{26}$ Autoimmune Diseases Research Unit, Department of Internal Medicine, BioCruces Health Research Institute, Hospital Universitario Cruces, University of the Basque Country, Barakaldo, Spain;

${ }^{27}$ Josep Font Autoimmune Diseases Laboratory, IDIBAPS, Department of Autoimmune Diseases, Hospital Clínic, Barcelona, Spain;

${ }^{28}$ Emory University School of Medicine, Division of Rheumatology, Atlanta, Georgia, USA

${ }^{29}$ Division of Rheumatology, Department of Internal Medicine, Istanbul Medical Faculty, Istanbul University, Istanbul, Turkey;

${ }^{30}$ UCSD School of Medicine, La Jolla, CA, USA;

${ }^{31}$ Department of Rheumatology, Rigshospitalet, Copenhagen University Hospital, Blegdamsvej 9, 2100, Copenhagen, Denmark;

This article is protected by copyright. All rights reserved. 
${ }^{32}$ University of Manitoba, Winnipeg, Manitoba, Canada;

${ }^{33}$ Medical University of South Carolina, Charleston, South Carolina, USA;

${ }^{34}$ Hospital for Joint Diseases, NYU, Seligman Centre for Advanced Therapeutics, New York NY;

${ }^{35}$ Department of Medicine, Queen Elizabeth II Health Sciences Centre and Dalhousie University, Halifax, Nova Scotia, Canada.

\section{Financial support:}

John.G. Hanly (Canadian Institutes of Health Research grant MOP-88526)

Dr. Sang-Cheol Bae's work was supported in part by an unrestricted grant (Hanyang University 201600000001387).

Dr. Caroline Gordon's work was supported by Lupus UK and the NIHR /Wellcome Trust Clinical Research Facility

The Hopkins Lupus Cohort is supported by the NIH (grant AR43727 and 69572).

The Montreal General Hospital Lupus Clinic is partially supported by the Singer Family Fund for Lupus Research.

Dr. Clarke holds The Arthritis Society Chair in Rheumatic Diseases at the University of Calgary.

This article is protected by copyright. All rights reserved. 
Dr. Paul R. Fortin presently holds a tier 1 Canada Research Chair on Systemic Autoimmune Rheumatic Diseases at Université Laval, and part of this work was done while he was still holding a Distinguished Senior Investigator of The Arthritis Society.

Dr. Bruce is supported by Arthritis Research UK, the National Institute for Health Research Biomedical Research Unit Funding Scheme and The NIHR Manchester Biomedical Research Centre and the NIHR/Wellcome Trust Clinical Research Facility at Central Manchester Foundation Trust. The views expressed in this publication are those of the author(s) and not necessarily those of the NHS, the National Institute for Health Research or the Department of Health.

Dr. Soren Jacobsen is supported by the Danish Rheumatism Association (A1028) and the Novo Nordisk Foundation (A05990).

Dr. Ramsey-Goldman's work was supported by the NIH (grants 5UL1TR001422-02, formerly 8UL1TR000150 and UL-1RR-025741, K24-AR-02318, and P60AR064464 formerly P60-AR-48098).

Dr. Mary Anne Dooley's work was supported by the NIH grant RR00046.

Dr. Ruiz-Irastorza is supported by the Department of Education, Universities and Research of the Basque Government.

Drs. Li Su and Vernon Farewell's work was supported by MRC (UK) funding U105261167.

This article is protected by copyright. All rights reserved. 
Address Correspondence and Reprints to: Dr. John G Hanly, Division of Rheumatology, Nova Scotia Rehabilitation Centre ( $2^{\text {nd }}$ Floor), 1341 Summer Street, Halifax, Nova Scotia, Canada, B3H 4K4.

Telephone: (902) 473 3818; $\quad$ Fax: (902) 473 7019;

Email: john.hanly@nshealth.ca

Key words: Systemic lupus erythematosus, Cerebrovascular events, Inception cohort, Outcomes research

\section{Abstract}

Objective: To determine the frequency, associations and outcomes of cerebrovascular events (CerVEs) in a multi-ethnic/racial, prospective, SLE disease inception cohort.

Methods: Patients were assessed annually for 19 neuropsychiatric (NP) events including 5 types of CerVEs: (i) Stroke; (ii) Transient ischemia; (iii) Chronic multifocal ischemia; (iv) Subarachnoid/intracranial hemorrhage; (v) Sinus thrombosis. Global disease activity (SLEDAI-2K), SLICC/ACR damage index (SDI) and SF-36 scores were collected. Time to event, linear and logistic regressions and multi-state models were used as appropriate.

Results: Of 1,826 SLE patients, $88.8 \%$ were female, $48.8 \%$ Caucasian, mean \pm SD age 35.1 \pm 13.3 years, disease duration $5.6 \pm 4.2$ months and follow-up $6.6 \pm 4.1$ years. CerVEs were the fourth most frequent NP event: 82/1,826 (4.5\%) patients had 109 events, $103 / 109(94.5 \%)$ were attributed to SLE and 44/109 (40.4\%) were identified at This article is protected by copyright. All rights reserved. 
enrollment. The predominant events were stroke $[60 / 109(55.0 \%)]$ and transient ischemia [28/109 (25.7\%)]. CerVEs were associated with other NP events attributed to SLE $(H R \quad(95 \% \mathrm{Cl}):(3.16 ; 1.73-5.75) \quad(p<0.001)$, non-SLE NP $(2.60 ; 1.49-4.51)$ $(p<0.001)$, African ancestry at US SLICC sites $(2.04 ; 1.01-4.13)(p=0.047)$ and organ damage $(p=0.041)$. Lupus anticoagulant increased the risk of first stroke and sinus thrombosis $[2.23(1.11,4.45) \mathrm{p}=.024]$ and TIA $[3.01(1.15,7.90) \mathrm{p}=0.025]$. Physician assessment indicated resolution or improvement in the majority but patients reported sustained reduction in SF-36 summary and subscale scores following CerVEs $(P<0.0001)$.

Conclusion: CerVEs, the fourth most frequent NP event in SLE, are usually attributable to lupus. In contrast to good physician reported outcomes, patients report a sustained reduction in health-related quality of life following CerVEs.

\section{Significance and Innovation}

$>$ A large, international, multi-ethnic/racial, disease inception cohort of SLE patients was established for the study of clinical outcomes and pathogenic mechanisms of nervous system disease.

$>$ In this study we report on the frequency, attribution, clinical and autoantibody associations of all cerebrovascular events in 1,826 SLE patients with a mean followup pf 6.6 years.

This article is protected by copyright. All rights reserved. 
> The most frequent cerebrovascular events were stroke and transient ischemia, the majority of which were attributable to SLE rather than atherosclerosis or other causes.

Cerebrovascular events were associated with a significant and sustained reduction in patient self-report health related quality of life even when adjusted for potential confounders.

Neuropsychiatric (NP) events are frequent in patients with systemic lupus erythematosus (SLE) $)^{1-5}$. The attribution of individual NP events to SLE and non-SLE causes is challenging. Approximately one-third of all NP events are directly attributed to SLE, although the attribution rate varies between individual manifestations ${ }^{6}$. Regardless of attribution, NP events are associated with a negative impact on health-related quality of life (HRQoL) in both cross-sectional ${ }^{6}$ and longitudinal ${ }^{7}$ studies. Thus, improving clinical outcomes in SLE patients must include identification, causal attribution and treatment of NP events. In the absence of controlled clinical trials, large observational cohort studies with careful documentation of NP events and their attribution, treatment and outcomes provides insight into this complex aspect of SLE.

Vascular disease, including involvement of the cerebral circulation, is a frequent cause of morbidity and mortality in SLE. Cerebrovascular events (CerVEs) are reported in 5$18 \%$ of patients in previous cohort studies ${ }^{2-5,8}$. Potential etiologies include procoagulant factors due to SLE (e.g. antiphospholipid antibodies, endothelial activation This article is protected by copyright. All rights reserved. 
and vasculitis) and factors which promote accelerated atherosclerosis (e.g. hypertension, hyperlipidemia and SLE itself). The relative contribution of these factors and the outcome of clinical CerVEs in a general lupus population have not been well documented.

In the present study, we determined the frequency, characteristics, clinical and autoantibody associations and outcome assessed by physicians and patients of CerVEs in a large, multi-ethnic/racial, prospective, inception cohort of SLE patients.

\section{Patients and Methods}

Research study network: The study was conducted by the Systemic Lupus International Collaborating Clinics (SLICC) ${ }^{9}$, a network of 38 investigators in 36 academic medical centers in 12 countries. Data were collected per protocol at enrollment and annually, submitted to the coordinating centre in Halifax, Nova Scotia, Canada and entered into a centralized Access database. Appropriate procedures ensured data quality, management and security. The Nova Scotia Health Authority central zone Research Ethics Board, Halifax, and each of the participating centers' institutional research ethics review boards approved the study.

Patients: Patients fulfilled the ACR SLE classification criteria for $\operatorname{SLE}^{10}$, the date of which was used as the date of diagnosis, and provided written informed consent.

This article is protected by copyright. All rights reserved. 
Enrollment was permitted up to 15 months following the diagnosis. Demographic variables, education and medication history were collected. Lupus-related variables included the SLE Disease Activity Index 2000 (SLEDAI-2K) ${ }^{11}$ and SLICC/ACR damage index $(\mathrm{SDI})^{12}$. Laboratory testing included hematological, biochemical and immunological variables required to determine SLEDAI-2K and SDI scores.

Neuropsychiatric (NP) events: An enrollment window extended from 6 months prior to the diagnosis of SLE up to the actual enrollment date. NP events were characterized within this window using the ACR case definitions for 19 NP syndromes ${ }^{13}$. These were diagnosed by clinical evaluation supported by investigations, if clinically warranted, as per the guidelines. Patients were reviewed annually with a 6-month window around the anticipated assessment date. New NP events and the status of previous NP events since the last study visit were determined at each assessment.

The ACR case definitions ${ }^{13}$ include 5 types of CerVEs: (i) Stroke; (ii) Transient ischemia; (iii) Chronic multifocal ischemia; (iv) Subarachnoid and intracranial hemorrhage; (v) Sinus thrombosis. Recurring CerVEs and other NP events within the enrollment window or within a follow-up assessment period were recorded once. The date of the first episode was taken as the onset of the event.

Attribution of NP events: In keeping with other publications on NP events within the SLICC NPSLE inception cohort, the same decision rules were used to determine the attribution of all NP events ${ }^{6,14}$. Factors considered in the decision rules included: (i) This article is protected by copyright. All rights reserved. 
temporal onset of NP event(s) in relation to the diagnosis of SLE; (ii) concurrent nonSLE factor(s), such as potential causes ("exclusions") or contributing factors ("associations") for each NP syndrome in the glossary for the ACR case definitions of NP events ${ }^{13}$; and (iii) "common" NP events which are frequent in normal population controls as described by Ainiala et $\mathrm{al}^{8}$. These include isolated headaches, anxiety, mild depression (mood disorders failing to meet criteria for "major depressive-like episodes"), mild cognitive impairment (deficits in less than 3 of the 8 specified cognitive domains) and polyneuropathy without electrophysiological confirmation. Two attribution decision rules of different stringency (models $A$ and $B$ ) were used ${ }^{6,14}$.

Attribution Model A: NP events which had their onset within the enrollment window and had no "exclusions" or "associations" and were not one of the NP events identified by Ainiala ${ }^{8}$ were attributed to SLE.

Attribution Model B: NP events which had their onset within 10 years of the diagnosis of SLE and were still present within the enrollment window and had no "exclusions" and were not one of the NP events identified by Ainiala ${ }^{8}$ were attributed to SLE.

NP events that fulfilled criteria for model A (most stringent) or for model B (least stringent) were attributed to SLE. By definition, all NP events attributed to SLE using model A were included in the NP events using model B. Those events which did not fulfill these criteria were classified as a non-SLE NP event.

Outcome of CerVEs: A physician generated 7-point Likert scale was completed at each follow-up assessment and compared the change in CerVE between onset and This article is protected by copyright. All rights reserved. 
follow-up (1=patient demise, $2=$ much worse, $3=$ worse, $4=$ no change, $5=$ =improved, $6=$ much improved, $7=$ resolved $)^{15}$. A patient generated SF-36 questionnaire was completed at each assessment and provided subscale, mental (MCS) and physical (PCS) component summary scores ${ }^{15,16}$, which were not available to physicians at their assessments.

Autoantibodies: Lupus anticoagulant (LAC), IgG anticardiolipin, anti- $\beta_{2}$ glycoprotein-I, anti-ribosomal P (anti-P) and anti-NR2 glutamate receptor antibodies were measured at the Oklahoma Medical Research Foundation, USA ${ }^{17-20}$.

Statistical analysis: Cumulative incidence estimation for first and recurrent CerVE used the Kaplan-Meier method. Cox regression, with time as age in years, was used to analyze time to SLE CerVE (attributed by Model B and stratified with different baseline risks for first-ever or recurrent SLE CerVEs). Hazard ratios (HR) and 95\% confidence intervals $(\mathrm{Cl})$ were calculated. Due to sparse data, logistic regression with generalized estimating equations (GEE) estimation was used to analyze grouped Likert scale outcomes ( $\geq 5$ vs. $\leq 4)$ for unresolved SLE CerVEs. Cox regression was also used for analyzing the time to resolution as it examines how quickly the CVD events resolved while the analysis of the Likert scale outcome examines the probability of being improved (but not resolved) at a specific time point. Covariates included sex, age at diagnosis, disease duration (in years), race/ethnicity, SLICC sites, education, ACR criteria at enrollment, SLEDAI-2K (without NP variables), SDI (without NP variables),

This article is protected by copyright. All rights reserved. 
antibodies at baseline and follow-up assessments (lupus anticoagulant, anticardiolipin, anti- $\beta_{2}$ glycoprotein-I, anti-ribosomal $P$, anti-NR2), medication use since last assessment (corticosteroids, antimalarials, immunosuppressants, anticoagulants), nephrotic syndrome, and other ongoing NP events. For analyses of the physicianassessed outcomes of CerVEs, history of SLE CerVEs, CerVE onset in enrollment window, SLE-attribution, and sub-types of CerVEs were also examined. For SF-36 scores, visit number, patient status by CerVE and other NP events were also included. Hypothesis testing utilized Wald's tests (Cox regression analysis) and Score tests (GEE analyses). An estimated multi-state model, with states defined by Likert scale scores, provided estimated probabilities of being in states at fixed times after a SLE CerVE occured. Transitions were restricted to those between adjacent states (change in score of 1 or -1 ) but occurred in continuous time, allowing moves of $>1$ state between assessments. Resolution was a final (absorbing) state. Piecewise constant transition rates were assumed with rates within 2 years after onset of a SLE CerVE differing from rates subsequently. For analyses of longitudinal SF-36 subscale and summary scores, linear regression with GEE estimation allowed for correlation of observations within patients.

\section{Results}

Patients: 1,826 patients were recruited between October 1999-December 2011, from centers in the United States $(n=539(29.5 \%))$, Europe $(n=477(26.1 \%))$ Canada $(n=418$ $(22.9 \%))$, Mexico $(n=223(12.2 \%))$, and Asia $(n=169(9.3 \%))$ (Table 1). The number of

This article is protected by copyright. All rights reserved. 
patient assessments varied from 1 to 18 with a mean follow-up of $6.6 \pm 4.1$ years and final assessment followup in December 2015.

Neuropsychiatric (NP) manifestations: NP events ( $\geq 1)$ occurred in 929/1,826 (50.9\%) patients and 476/1,826 (26.1\%) had $\geq 2$ events over the study period. There were 1,844 unique NP events, encompassing all 19 NP syndromes in the ACR case definitions ${ }^{13}$. The proportion of NP events attributed to SLE varied from $17.7 \%$ (attribution model A) to $31.1 \%$ (attribution model B) and occurred in $12.9 \%$ (model A) to $20.7 \%$ (model B) of patients. Of the 1,844 unique NP events, 1,690 (91.6\%) involved the central nervous system and $154(8.4 \%)$ the peripheral nervous system ${ }^{13}$. The classification of events into diffuse and focal was $1,424(77.2 \%)$ and $420(22.8 \%)$ respectively ${ }^{14}$.

Cerebrovascular event frequency and characteristics: There were 109 CerVEs in $82 / 1,826(4.5 \%)$ patients. Forty-three of the 109 (39.4\%) events in 34/82 (41.5\%) patients were attributed to SLE using model A, and 103/109 (94.5\%) events in 79/82 (96.3\%) patients were attributed to SLE using model B attribution rules. Forty-four of the 109 (40.4\%) CerVEs were identified at the enrollment visit and the remainder over the ensuing follow-up. The predominant events were stroke [60/109 (55.0\%)] and transient ischemia [28/109 (25.7\%)] followed by subarachnoid/intracranial hemorrhage [9/109 $(8.3 \%)]$, chronic multifocal ischemia [9/109 (8.3\%)] and sinus thrombosis [3/109 (2.8\%)]. The estimated cumulative incidence of any CerVE and those attributed to SLE (model B attribution rule) after 10 years was $5.0 \% \quad(95 \% \mathrm{Cl}=[3.9 \%, 6.2 \%])$ and $4.9 \%$ This article is protected by copyright. All rights reserved. 
$(95 \% \mathrm{Cl}=[3.7 \%, 6.0 \%])$ respectively (Figure 1$).$ In patients with a previous SLE attributed CerVE, the estimate at 5 years after first CerVE was $11.4 \%(95 \% \mathrm{Cl}=[3.0 \%, 19.1 \%])$. The incidence rate of first SLE CerVE was 5.8/1000 person years and the incidence of recurrence was 32.7/1000 person years. There were 3 deaths in the CerVE group, 2 attributed to intra-cranial hemorrhage and 1 to cardiopulmonary arrest.

\section{Clinical and laboratory associations with SLE cerebrovascular events: After} excluding one SLE CerVE occurring 2 years before SLE diagnosis, 102 SLE CerVEs were used for analysis. As 8 patients had two SLE CerVEs occurring on the same dates, the two events for these patients were only counted once in the Cox regression analyses. Overall, there were 78 SLE CerVEs available for examining the risk of firstever SLE CerVE and 16 SLE CerVEs available for examining the risk of recurrent SLE CerVE.

Univariate analysis revealed a positive association [HR $(95 \% \mathrm{Cl})$ ] between CerVEs attributed to SLE and prior SLE CerVEs $4.4(2.1,9.0)$. Stratifying on this factor, other positive associations were with shorter disease duration [HR for 5 years after SLE diagnosis vs time at SLE diagnosis $0.20(0.12,0.33)]$, African ancestry at US sites [2.0 $(1.03,3.90)]$, SDI score without NP variables $[1.21(1.01,1.45)]$, non-SLE NP events [1.70 $(1.03,2.80)]$ and previous SLE NP events $[2.23(1.32,3.78)]$. Atrial fibrillation was present in 2 patients with CerVEs, 1 with a TIA and another with a stroke.

This article is protected by copyright. All rights reserved. 
Variables that were significant in the univariate analyses were included in the subsequent multivariate analyses. To avoid excluding observations due to missing values in covariates (e.g. patients with disease duration $<6$ months at enrollment did not have SDI scores available), we first fitted a base model that included disease duration, race/ethnicity/location and other ongoing NP events. An association with shorter disease duration was again found due to the fact that most of the CerVEs occurred within the enrollment window. When an indicator variable representing the enrolment window was introduced into the model, disease duration had no demonstrable effect. The results of multivariate regressions examining the associations with CerVEs attributed to SLE using the base model are summarized in Table 2. There was a greater risk of a CerVE attributed to SLE in patients with concurrent NP events attributed to SLE [aseptic meningitis (1), mononeuropathy (1), movement disorder (1), polyneuropathy (1), seizures (4), acute confusion (1), cognitive dysfunction (2), mood disorder (6) and psychosis (1), $\mathrm{p}<0.001)$ ], concurrent non-SLE NP events [headache (18), movement disorder (1), plexopathy (1), polyneuropathy (7), acute confusion (1), anxiety (5), cognitive dysfunction (2) and mood disorder (5), $\mathrm{p}<0.001)$ ], and African ancestry at US sites $(p=0.047)$. Note that the prior and recurrent SLE CerVE events are allowed to have different baseline hazards (strata), therefore the effect of prior SLE CerVE on the risk of SLE CerVE is not presented as a hazard ratio in Table 2. We further examined the associations of SDI scores, medications and autoantibodies in addition to the base model and found that increased cumulative organ damage scores (excluding NP variables) were positively associated with the risk of SLE CerVE $(p=0.041)$. There was no evidence of significant associations of SLE CerVEs with

This article is protected by copyright. All rights reserved. 
medications and autoantibodies (treated as time-varying variables) after adjusting for the variables in the base model.

Additional analyses examined specific associations between CerVEs attributed to SLE and baseline antiphospholipid antibodies using data on 69 SLE CerVEs with available autoantibody data. There was a positive, albeit borderline statistically significant, association between LAC at enrolment and risk of first SLE CerVE $[1.77(0.99,3.16)$ $\mathrm{p}=0.054)$ ]; the association between baseline LAC and recurrent SLE CVD was also positive but not significant $[H R=1.7(0.29,9.88)$, global test for interaction $p=0.968]$. This was likely due to the small number of events and the greater use of anticoagulants following the initial CerVE (any anticoagulant 12/13 (92\%), warfarin 5/13 (39\%)) compared to at the time of the initial events [any anticoagulant 19/56 (68\%), warfarin 4/56 (7\%)]. A similar analysis restricted to stroke and sinus thrombosis, also demonstrated a relationship between LAC at enrolment and the first 36 events [2.23 $(1.11,4.45) p=.024]$ but was insignificant for the 7 subsequent events $[2.21(0.13,36.9)$ $\mathrm{p}=0.58]$. When the analysis was restricted to TIAs, a relationship was found for the 18 first events $[3.01(1.15,7.90) p=0.025]$ but there was insufficient data to examine associations with the 2 subsequent TIAs. There was no association with other autoantibodies.

Clinical outcome of cerebrovascular events: Excluding TIAs there were 74 SLE CerVEs available for time to resolution analysis. Of these, $47(63.5 \%)$ were resolved by This article is protected by copyright. All rights reserved. 
the end of study (36 strokes, 5 chronic multifocal disease, 4 subarachnoid and intracranial hemorrhage, and 2 sinus thrombosis). Figure $2 a$ illustrates the probability of CerVEs (excluding TIAs) not resolving over time. For stroke the estimated probability at 10 years was $11.6 \% \quad[95 \% \mathrm{Cl}[3.6 \%, 37.3 \%))$; for chronic multifocal disease/subarachnoid and intracranial hemorrhage/sinus thrombosis it was $19.8 \%$ $([4.28 \%, 91.5 \%])$ and for the total group it was $11.64 \%([3.85 \%, 35.2 \%])$. Overall there were no predictors found to be associated with resolution of CerVE.

Figure $2 \mathrm{~b}$ summarizes the distribution of maximum and minimum Likert scale scores indicating physician assessment of outcome of CerVEs during follow-up. Two of the three patients who died had a total of three preceding CerVEs shortly prior to death and thus had both maximum and minimum Likert scores of 1 (patient demise). The third patient who died had a CerVE which improved over several years prior to death. For this patient the minimum and maximum scores were 1 (patient demise) and 6 (much improved) respectively. The estimated percentages, from a multi-state model of living patients with individual Likert scores between 2 and 7, at 5 years after the onset of a CerVE, were $0.5 \%, 0.6 \%, 10.8 \%, 11.3 \%, 5.8 \%, 71 \%$ respectively. The estimated percentages after 10 years were $0.5 \%, 0.4 \%, 7.2 \%, 6.9 \%, 3.4 \%, 81.7 \%$, respectively. Greater improvement in unresolved CerVEs was associated with CerVEs attributed to SLE (model A) $(p=0.005)$ and younger age $(p=0.02)$ in univariate logistic regression analyses for grouped Likert scores, after adjusting for time since CerVE onset. Similar findings were observed in the multivariate analyses.

This article is protected by copyright. All rights reserved. 
Cerebrovascular events and Health-Related Quality of Life: The association between CerVEs and SF-36 summary and sub-scale scores is illustrated in Figures 3 and 4 using data in three groups of patients over time: (i) SLE CerVEs (single or multiple, including TIAs) which occurred at or prior to the study assessment; (ii) any NP event other than an SLE CerVE occurring at or prior to the study assessment; (iii) patients who never had any NP event up to the study assessment. Once assigned, each patient retained the same group membership throughout the study unless they had a new or subsequent NP event which could trigger a change in group assignment. The lowest mean (SD) PCS score occurred in patients with SLE CerVEs [37.3 (11.5)] compared to patients with other NP events [40.7 (11.8)] and patients without NP events [43.9 (11.0)] [overall $p<0.0001$ after adjusting for time/visit, sex, age at SLE diagnosis, race/ethnicity/location, education, SLEDAI-2K and SDI (without NP variables) scores, corticosteroids, antimalarials and immunosuppressant use since last assessment]. Similar but less marked differences in mean (SD) MCS scores were seen with the same group assignment [43.1 (12.5) vs 45.1 (12.2) vs 48.8 (10.8)] (overall $p<0.0001$ after adjustments) (Figure 3A). For both PCS and MCS scores there were significant differences between groups (i) and (iii) ( $p=0.0034$ and $p<0.0001$, respectively) but not between groups (i) and (ii) ( $p>0.05)$. The mean group differences in individual SF-36 subscale scores in the same three groups of patients (Figure 3B), indicated that all eight self-reported health domains were lowest in patients with SLE CerVEs compared to the other two groups. Finally, the group differences in PCS and MCS scores over time (Figure 4) persisted for 10 years of follow-up (global p-values for group effects $<0.0001$

This article is protected by copyright. All rights reserved. 
after adjustments although there was some evidence for small numerical variation in the PCS group differences over time (global p-value for linear interaction terms of time and NP groups $=0.01)$ with none for the MCS group differences over time.

Multivariate analysis for adjustment variables also identified a number of factors [regression coefficient $(95 \% \mathrm{Cl})$ ] associated with SF-36 summary scores (data not shown). Female sex [-3.12 (-4.54, -1.70), $\mathrm{P}<.0001]$, older age at SLE diagnosis [-0.20 ($0.24,-0.17), P<.0001]$, Caucasians at US sites $[-3.52(-5.22,-1.83)]$ and African ancestry at non-US sites $[-2.26(-4.05,-0.47)$ global $p<.0001]$, higher SLEDAI-2K [-1.03 $(-1.28,-0.78) p<.0001]$ and SDI scores computed without NP variables [SDI $4+$ vs. $0=-$ $4.08(-5.93,-2.23)$ global $p<.0001]$, and corticosteroid use $[-2.04(-2.64,-1.43) p<.0001]$ were associated with lower PCS scores. Conversely, patients with Asian [3.44 (2.21, $4.67)$ and Hispanic race/ethnicity $[3.46(2.12,4.81)$, global $p$ for race/ethnicity effect $<.0001]$ and post-secondary education $[1.86(0.93,2.79) \mathrm{p}<.0001]$ had higher PCS scores. For MCS, female sex [-1.57 $(-3.09,-0.05) \mathrm{p}=0.043]$, higher SLEDAI-2K scores $[-0.57(-0.87,-0.26), p=0.0003]$ and corticosteroid use $[-0.89(-1.54,0.23) p=0.0085)$ were associated with lower scores. Conversely, patients with Asian race/ethnicity had higher MCS scores [2.35 $(1.06,3.64)$ global $p$ for race/ethnicity effect=0.008].

This article is protected by copyright. All rights reserved. 


\section{Discussion}

Although vascular NP events are not the most frequent of neurological presentations in SLE patients, they are one of the more serious. CerVEs are not included in the revised ACR classification criteria for $\operatorname{SLE}^{10}$ (seizures and psychosis) or in the more recent SLICC classification criteria which has six NP manifestations ${ }^{21}$. A meta-analysis involving 5,057 SLE patients using ACR case definitions for CerVEs, found an overall prevalence of $5 \%(3.6 \%-7.2 \%)^{22}$. In our study, CerVEs were ranked the fourth most common NP event with a prevalence of $4.5 \%$. The most frequent types of CerVEs were strokes and TIAs and the majority, regardless of type, was attributed to SLE (96.3\% of CerVEs using attribution model B) and associated with LAC. The attribution to SLE was higher than for more frequent NP events in the SLICC cohort such as isolated headache $(0 \%)^{23}$, mood disorders $(38.3 \%)^{24}$ and seizures $(85.7 \%)^{25}$. Although risk factors for atherosclerosis have been reported in the $\operatorname{cohort}^{26}$, these was not causally related to CerVEs. As most of the events occurred early in the disease course, it is possible that CerVEs occurring later in the disease may be more frequently attributed to atherosclerosis but further follow-up is required to confirm this.

In addition to the association with LAC, CerVEs were associated with clinical variables. In particular, the occurrence of a prior event was predictive of a subsequent event with a five-fold increase. As reported with other NP events ${ }^{23-25}$, CerVEs in SLE patients frequently do not occur in isolation but rather in association with concurrent NP events attributed to both SLE and non-SLE causes. The association with increased organ

This article is protected by copyright. All rights reserved. 
damage, which has been reported previously ${ }^{27}$, underlines the link of NPSLE with serious events in other organ systems either attributed to SLE itself, complications of therapy or comorbid factors. Finally, the association between CerVEs and patients of African ancestry at US SLICC sites suggests contributions from both genetic and environmental factors.

Few studies describe the clinical outcome of stroke in SLE ${ }^{28-30}$, frequently utilizing health administrative data on hospitalized patients ${ }^{29,30}$. In these studies, the functional outcome was comparable to the general population ${ }^{28-30}$ and better than in patients with rheumatoid arthritis ${ }^{29}$, although both comparator populations were older. In the current study, physician assessment of outcome following CerVEs was generally favourable. In contrast, the assessment of health status by patients with CerVEs, as reflected by both summary and subscale scores of the SF-36, indicated a significant and sustained reduction in HRQoL. Although TIAs were not included in physician assessment of outcome, they were included in health status scores, further highlighting the difference in assessment of outcomes between physicians and patients. Discordance of health concerns between patients and physicians has been demonstrated in a recent study of SLE patients ${ }^{31}$. Specifically, the predominant concerns of patients were function and fatigue, whereas physicians focused on SLE-related factors. A systemic review of qualitative research studies in SLE ${ }^{32}$ has emphasized the significant psychological impact of the disease which can be addressed in part through participation in selfmanagement programs ${ }^{33}$.

This article is protected by copyright. All rights reserved. 
There are some limitations to the current study. First, the absence of a control population precludes more definitive interpretation of the frequency of CerVEs in SLE patients. This was not feasible and is compensated by the size of the inception cohort, the prospective study design and standardized data collection. Second, specialized investigations such as neuroimaging were not routinely performed but left to the discretion of individual investigators. Likely, the universal application of such investigations would have detected additional intra-cranial abnormalities but our protocol more accurately reflects what is done in clinical practice. Third, the unavailability of autoantibody data for some patients may have limited our ability to fully assess their association with CerVEs. Fourth, the potential contribution of accelerated atherosclerosis to CerVEs could not be fully evaluated and longer term follow-up is required. Finally, missing data due to loss to follow-up or death is an inevitable limitation of observational cohort studies but our results are relevant to the patient population that was alive and still under follow-up. If there was a large amount of missing covariate data (e.g. SDI scores), the analyses were performed with and without covariates. When autoantibodies were unavailable over follow-up assessments, we applied the 'last observation carry forward' imputation.

Despite these limitations, the results emphasize many salient features of CerVEs in SLE. This includes their predilection for presenting early in the disease course, their

This article is protected by copyright. All rights reserved. 
association with clinical and serological variables and their short and long-term impact on HRQoL.

\section{References}

1. Ainiala H, Loukkola J, Peltola J, Korpela M, Hietaharju A. The prevalence of neuropsychiatric syndromes in systemic lupus erythematosus. Neurology 2001;57:496-500.

2. Brey RL, Holliday SL, Saklad AR, et al. Neuropsychiatric syndromes in lupus: prevalence using standardized definitions. Neurology 2002;58:1214-20.

3. Hanly JG, McCurdy G, Fougere L, Douglas JA, Thompson K. Neuropsychiatric events in systemic lupus erythematosus: attribution and clinical significance. $\mathrm{J}$ Rheumatol 2004;31:2156-62.

4. Sanna G, Bertolaccini ML, Cuadrado MJ, Laing H, Mathieu A, Hughes GR. Neuropsychiatric manifestations in systemic lupus erythematosus: prevalence and association with antiphospholipid antibodies. J Rheumatol 2003;30:985-92.

5. Sibbitt WL, Jr., Brandt JR, Johnson CR, et al. The incidence and prevalence of neuropsychiatric syndromes in pediatric onset systemic lupus erythematosus. J Rheumatol 2002;29:1536-42.

6. Hanly JG, Urowitz MB, Sanchez-Guerrero J, et al. Neuropsychiatric events at the time of diagnosis of systemic lupus erythematosus: an international inception cohort study. Arthritis Rheum 2007;56:265-73.

This article is protected by copyright. All rights reserved. 
7. Hanly JG, Urowitz MB, Su L, et al. Prospective analysis of neuropsychiatric events in an international disease inception cohort of patients with systemic lupus erythematosus. Ann Rheum Dis 2010;69:529-35.

8. Ainiala $\mathrm{H}$, Hietaharju A, Loukkola J, et al. Validity of the new American College of Rheumatology criteria for neuropsychiatric lupus syndromes: a population-based evaluation. Arthritis Rheum 2001;45:419-23.

9. Isenberg D, Ramsey-Goldman R. Systemic Lupus International Collaborating Group--onwards and upwards? Lupus 2006;15:606-7.

10. Hochberg MC. Updating the American College of Rheumatology revised criteria for the classification of systemic lupus erythematosus. Arthritis Rheum $1997 ; 40: 1725$.

11. Gladman DD, Ibanez D, Urowitz MB. Systemic lupus erythematosus disease activity index 2000. J Rheumatol 2002;29:288-91.

12. Gladman D, Ginzler E, Goldsmith C, et al. The development and initial validation of the Systemic Lupus International Collaborating Clinics/American College of Rheumatology damage index for systemic lupus erythematosus. Arthritis Rheum 1996;39:363-9.

13. The American College of Rheumatology nomenclature and case definitions for neuropsychiatric lupus syndromes. Arthritis Rheum 1999;42:599-608.

14. Hanly JG, Urowitz MB, Su L, et al. Short-term outcome of neuropsychiatric events in systemic lupus erythematosus upon enrollment into an international inception cohort study. Arthritis Rheum 2008;59:721-9.

This article is protected by copyright. All rights reserved. 
15. Hanly JG, Urowitz MB, Jackson D, et al. SF-36 summary and subscale scores are reliable outcomes of neuropsychiatric events in systemic lupus erythematosus. Ann Rheum Dis 2011;70:961-7.

16. Thumboo J, Fong KY, Ng TP, et al. Validation of the MOS SF-36 for quality of life assessment of patients with systemic lupus erythematosus in Singapore. J Rheumatol 1999;26:97-102.

17. Merrill JT, Zhang HW, Shen C, et al. Enhancement of protein S anticoagulant function by beta2-glycoprotein I, a major target antigen of antiphospholipid antibodies: beta2-glycoprotein I interferes with binding of protein $S$ to its plasma inhibitor, C4b-binding protein. Thromb Haemost 1999;81:748-57.

18. Merrill JT, Shen C, Gugnani M, Lahita RG, Mongey AB. High prevalence of antiphospholipid antibodies in patients taking procainamide. J Rheumatol $1997 ; 24: 1083-8$

19. Erkan D, Zhang HW, Shriky RC, Merrill JT. Dual antibody reactivity to beta2glycoprotein I and protein S: increased association with thrombotic events in the antiphospholipid syndrome. Lupus 2002;11:215-20.

20. Hanly JG, Urowitz MB, Siannis F, et al. Autoantibodies and neuropsychiatric events at the time of systemic lupus erythematosus diagnosis: results from an international inception cohort study. Arthritis Rheum 2008;58:843-53.

21. Petri M, Orbai AM, Alarcon GS, et al. Derivation and validation of the Systemic Lupus International Collaborating Clinics classification criteria for systemic lupus erythematosus. Arthritis Rheum 2012;64:2677-86.

This article is protected by copyright. All rights reserved. 
22. Unterman A, Nolte JE, Boaz M, Abady M, Shoenfeld Y, Zandman-Goddard G. Neuropsychiatric syndromes in systemic lupus erythematosus: a meta-analysis. Semin Arthritis Rheum 2011;41:1-11.

23. Hanly JG, Urowitz MB, O'Keeffe AG, et al. Headache in systemic lupus erythematosus: results from a prospective, international inception cohort study. Arthritis Rheum 2013;65:2887-97.

24. Hanly JG, Su L, Urowitz MB, et al. Mood Disorders in Systemic Lupus Erythematosus: Results From an International Inception Cohort Study. Arthritis \& rheumatology 2015;67:1837-47.

25. Hanly JG, Urowitz MB, Su L, et al. Seizure disorders in systemic lupus erythematosus results from an international, prospective, inception cohort study. Ann Rheum Dis 2012;71:1502-9.

26. Urowitz MB, Gladman D, Ibanez D, et al. Atherosclerotic vascular events in a multinational inception cohort of systemic lupus erythematosus. Arthritis Care Res (Hoboken) 2010;62:881-7.

27. Calvo-Alen J, Alarcon GS, Tew MB, et al. Systemic lupus erythematosus in a multiethnic US cohort: XXXIV. Deficient mannose-binding lectin exon 1 polymorphisms are associated with cerebrovascular but not with other arterial thrombotic events. Arthritis Rheum 2006;54:1940-5.

28. Mok CC, Ho LY, To $\mathrm{CH}$. Annual incidence and standardized incidence ratio of cerebrovascular accidents in patients with systemic lupus erythematosus. Scand J Rheumatol 2009;38:362-8.

This article is protected by copyright. All rights reserved. 
29. Nguyen-Oghalai TU, Wu H, McNearney TA, Granger CV, Ottenbacher KJ.

Functional outcome after stroke in patients with rheumatoid arthritis and systemic lupus erythematosus. Arthritis Rheum 2008;59:984-8.

30. Ward MM. Outcomes of hospitalizations for myocardial infarctions and cerebrovascular accidents in patients with systemic lupus erythematosus. Arthritis Rheum 2004;50:3170-6.

31. Golder V, Ooi JJY, Antony AS, et al. Discordance of patient and physician health status concerns in systemic lupus erythematosus. Lupus 2017:961203317722412.

32. Sutanto B, Singh-Grewal D, McNeil HP, et al. Experiences and perspectives of adults living with systemic lupus erythematosus: thematic synthesis of qualitative studies. Arthritis Care Res (Hoboken) 2013;65:1752-65.

33. Drenkard C, Dunlop-Thomas C, Easley K, Bao G, Brady T, Lim SS. Benefits of a self-management program in low-income African-American women with systemic lupus erythematosus: results of a pilot test. Lupus 2012;21:1586-93.

This article is protected by copyright. All rights reserved. 
Table 1: Demographic and clinical manifestations of SLE patients at enrolment.

\begin{tabular}{|c|c|c|}
\hline \multicolumn{2}{|l|}{ Number of Patients } & \multirow{2}{*}{$\begin{array}{c}1826 \\
1622(88.8) \\
204(11.2)\end{array}$} \\
\hline Gender (\%) & $\begin{array}{l}\text { Female } \\
\text { Male }\end{array}$ & \\
\hline \multicolumn{2}{|c|}{ Age (years) (mean \pm SD) } & $35.1 \pm 13.3$ \\
\hline \multirow[t]{5}{*}{ Race/Ethnicity (\%) } & Caucasian & $891(48.8)$ \\
\hline & African ancestry & $306(16.8)$ \\
\hline & Asian & $275(15.1)$ \\
\hline & Hispanic & $282(15.4)$ \\
\hline & Other & $72(3.9)$ \\
\hline \multicolumn{2}{|c|}{ Single/Married/Other (\%) } & $818(44.9) / 767(42.1) / 237(13.0)$ \\
\hline \multicolumn{2}{|c|}{ Post secondary education (\%) } & $1064(61.9)$ \\
\hline \multicolumn{2}{|c|}{ Disease duration (months) (mean $\pm S D$ ) } & $5.6 \pm 4.2$ \\
\hline \multicolumn{2}{|c|}{ Number of ACR criteria (mean \pm SD) } & $4.9 \pm 1.1$ \\
\hline \multicolumn{3}{|c|}{ ACR manifestations (\%) } \\
\hline & Malar rash & $660(36.1)$ \\
\hline & Discoid rash & $227(12.4)$ \\
\hline & Photosensitivity & $652(35.7)$ \\
\hline & Oral/nasal ulcers & $677(37.1)$ \\
\hline & Serositis & $502(27.5)$ \\
\hline & Arthritis & $1368(74.9)$ \\
\hline & Renal disorder & $510(27.9)$ \\
\hline & Neurological disorder & $88(4.8)$ \\
\hline & Hematologic disorder & $1129(61.8)$ \\
\hline & Immunologic disorder & $1392(76.2)$ \\
\hline & Antinuclear antibody & $1731(94.8)$ \\
\hline \multicolumn{2}{|c|}{ SLEDAI-2K score (mean \pm SD) } & $5.3 \pm 5.4$ \\
\hline \multicolumn{2}{|c|}{ SLICC/ACR damage index score (mean \pm SD) } & $0.31 \pm 0.73$ \\
\hline \multicolumn{2}{|c|}{\begin{tabular}{l|l} 
Medications (\%) & Corticosteroids
\end{tabular}} & \\
\hline & Antimalarials & $1284(70.3)$ \\
\hline & Immunosuppressants & $1231(67.4)$ \\
\hline & & $732(40.1)$ \\
\hline & Antidepressants & $256(14.0)$ \\
\hline & Warfarin & $183(10.0)$ \\
\hline & Anticonvulsants & $96(5.3)$ \\
\hline & Antipsychotics & $80(4.4)$ \\
\hline & & $12(0.7)$ \\
\hline \multirow{2}{*}{ Autoantibodies (\%) } & Lupus anticoaqulant & $241 / 1174(20.5)$ \\
\hline & Anticardiolipin & 138/1142 (12.1) \\
\hline \multirow[t]{2}{*}{ - } & Anti- $\beta_{2}$ glycoprotein-I & $163 / 1142(14.3)$ \\
\hline & Anti-ribosomal P & $112 / 1136(9.9)$ \\
\hline 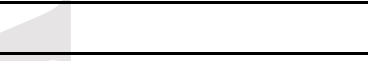 & Anti-NR2 & $130 / 1064(12.2)$ \\
\hline & & \\
\hline
\end{tabular}

This article is protected by copyright. All rights reserved. 


\begin{tabular}{|l|c|c|}
\hline Smoking (\%) & & $270 / 1824(14.8)$ \\
\hline Hypertension (\%) & & $627 / 1823(34.4)$ \\
\hline Diabetes (\%) & & $67 / 1808(3.7)$ \\
\hline Obese (\%) & & $548 / 1752(31.3)$ \\
\hline Hypercholesterolemia (\%) & & $648 / 1824(35.5)$ \\
\hline Family history of CAD (\%) & & $427 / 1826(23.4)$ \\
\hline
\end{tabular}

Table 2: Multivariate regression analysis for predictors of cerebrovascular events attributed to SLE (model B).

\begin{tabular}{|c|c|c|c|c|c|}
\hline Variable & & $\begin{array}{c}\text { Hazard } \\
\text { Ratio }\end{array}$ & $\begin{array}{l}\text { Hazard } \\
\text { Ratio } \\
\text { (lower } \\
95 \% \mathrm{Cl} \text { ) }\end{array}$ & $\begin{array}{l}\text { Hazard } \\
\text { Ratio } \\
\text { (upper } \\
95 \% \mathrm{Cl} \text { ) }\end{array}$ & $\begin{array}{l}\text { P-value } \\
\text { (Wald) }\end{array}$ \\
\hline \multirow{3}{*}{$\begin{array}{l}\text { Other ongoing } \\
\text { NP events(ref: } \\
\text { No NP events) }\end{array}$} & $\begin{array}{l}\text { Any SLE NP } \\
\text { events ongoing }\end{array}$ & 3.16 & 1.73 & 5.75 & $<.001$ \\
\hline & $\begin{array}{l}\text { All non-SLE NP } \\
\text { events ongoing }\end{array}$ & 2.60 & 1.49 & 4.51 & $<.001$ \\
\hline & overall (Wald) & & & & $<.001$ \\
\hline $\begin{array}{l}\text { Enrollment } \\
\text { window }\end{array}$ & Yes & 6.08 & 3.18 & 11.64 & $<.001$ \\
\hline Sex & Female & 0.70 & 0.41 & 1.21 & 0.200 \\
\hline $\begin{array}{l}\text { Disease } \\
\text { duration (years) }\end{array}$ & & 0.94 & 0.85 & 1.04 & 0.201 \\
\hline \multirow{7}{*}{$\begin{array}{l}\text { Race/Ethnicity/l } \\
\text { ocation (ref: } \\
\text { EU/CAN } \\
\text { Caucasian) }\end{array}$} & Asian & 0.67 & 0.28 & 1.62 & 0.376 \\
\hline & Hispanic & 1.29 & 0.67 & 2.48 & 0.454 \\
\hline & Other African & 1.43 & 0.64 & 3.19 & 0.381 \\
\hline & US African & 2.04 & 1.01 & 4.13 & 0.047 \\
\hline & US Caucasian & 0.95 & 0.46 & 1.97 & 0.899 \\
\hline & other & 1.04 & 0.34 & 3.16 & 0.943 \\
\hline & Global (Wald) test & & & & 0.337 \\
\hline
\end{tabular}

This article is protected by copyright. All rights reserved. 
Figure 1: The estimated cumulative incidence of initial $(A)$ and recurrent $(B)$ cerebrovascular events (CerVE). Events were attributed to SLE using attribution model B.

A

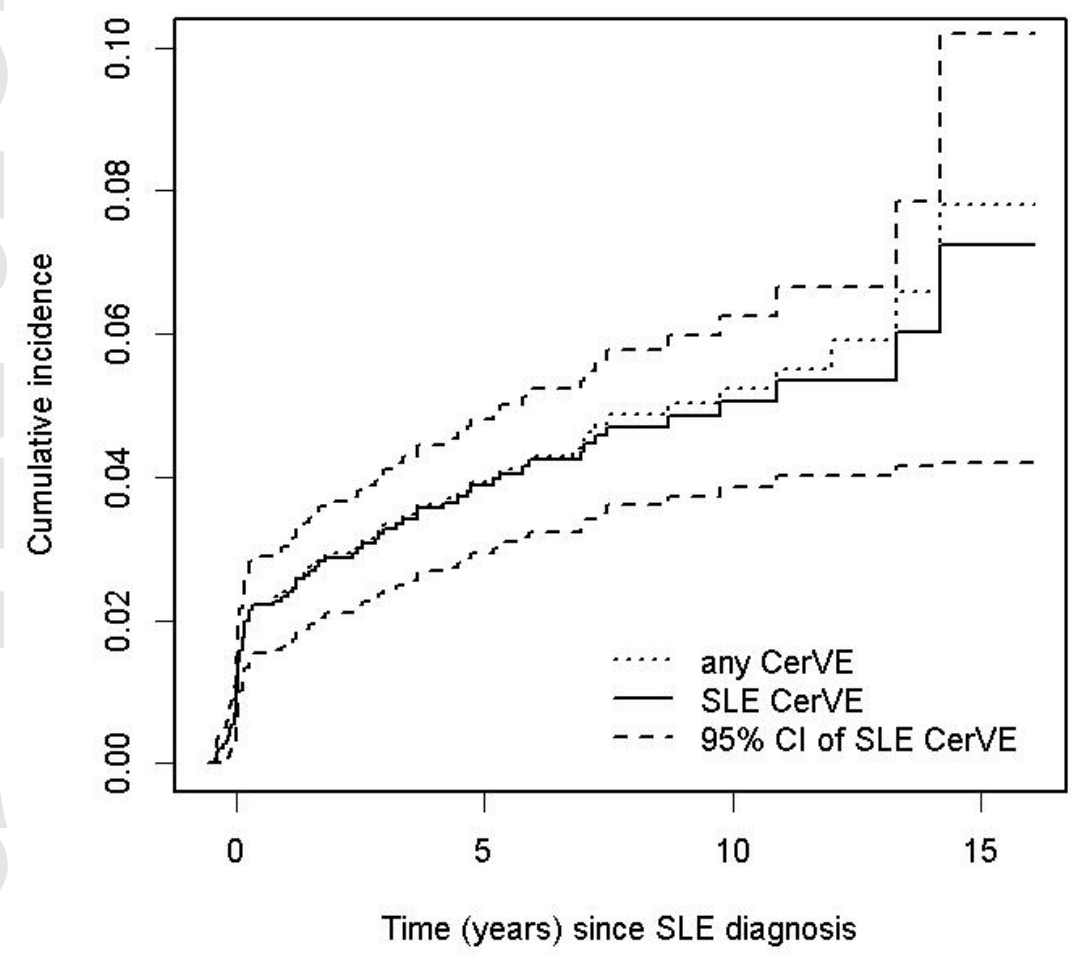

This article is protected by copyright. All rights reserved. 
B

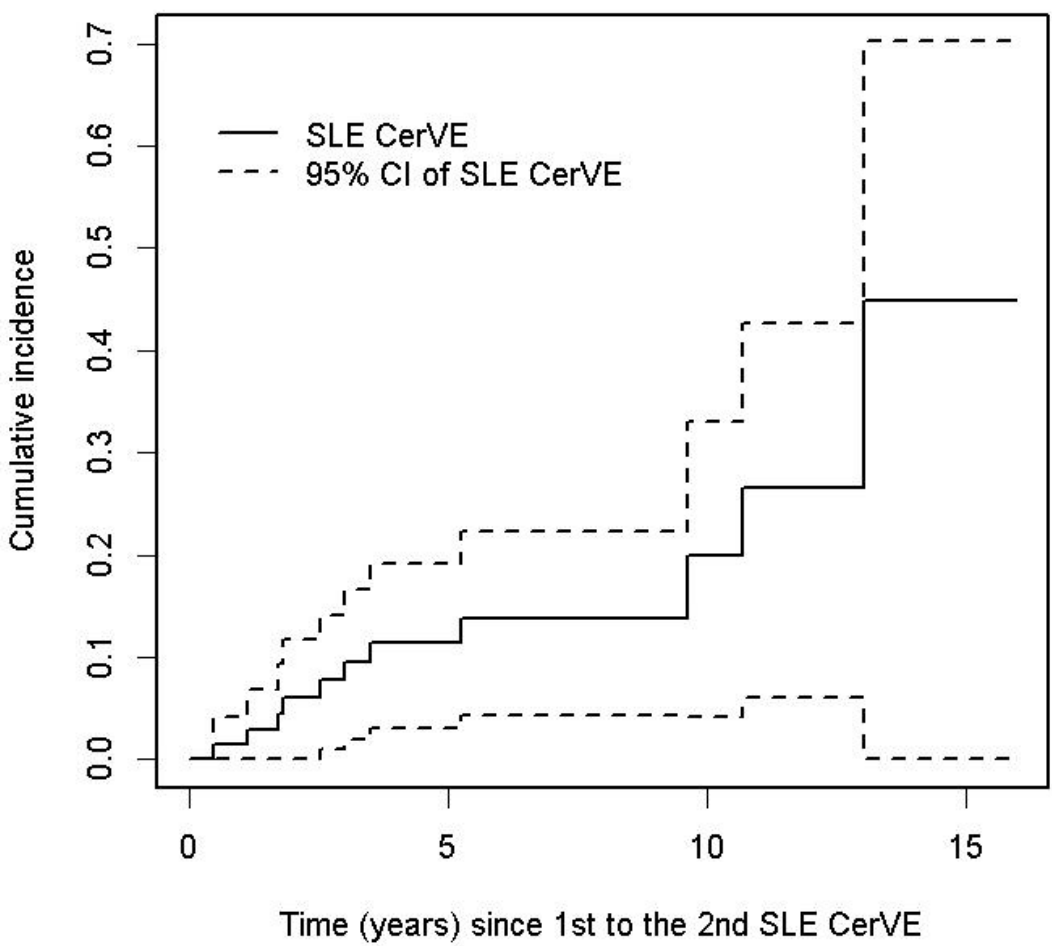

This article is protected by copyright. All rights reserved. 
Figure 2: Physician determined change in cerebrovascular events (CerVE) attributed to SLE (model B). A: Survival curves for resolution. B: The highest and lowest Likert scale scores over the duration of followup are shifted to the right indicated improvement.

A

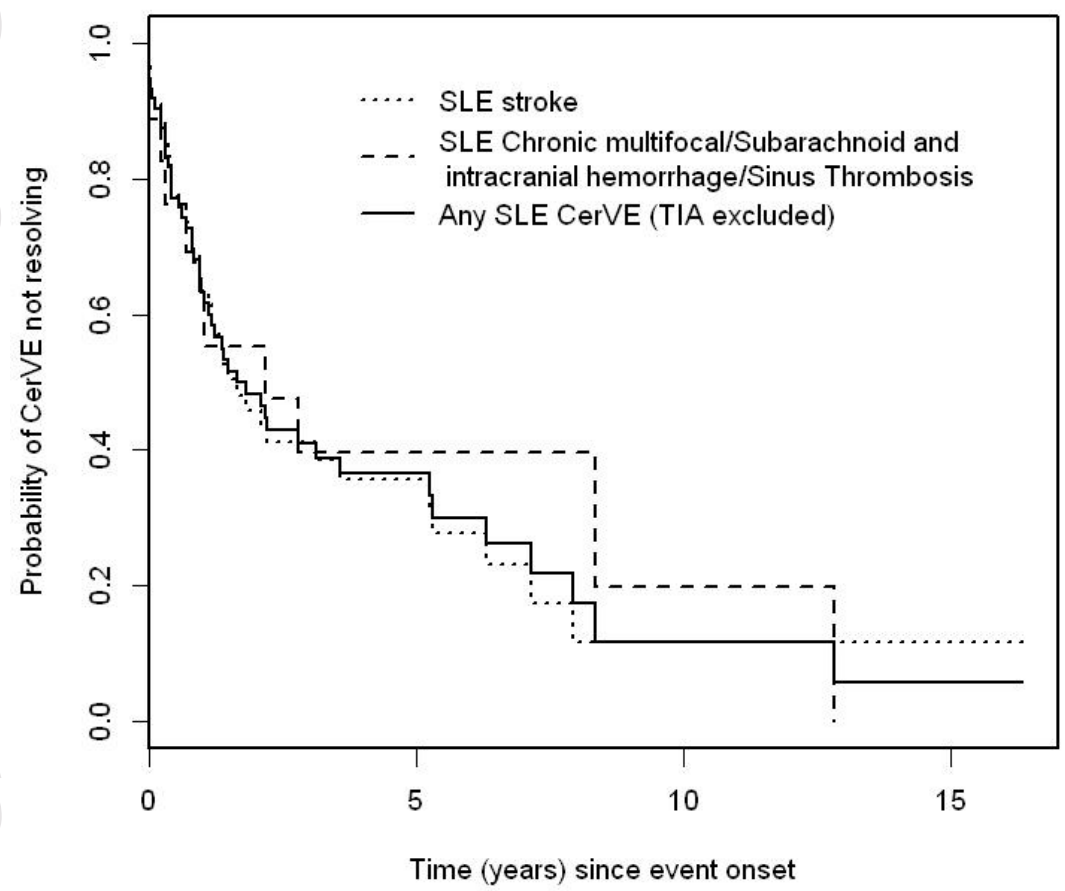

B

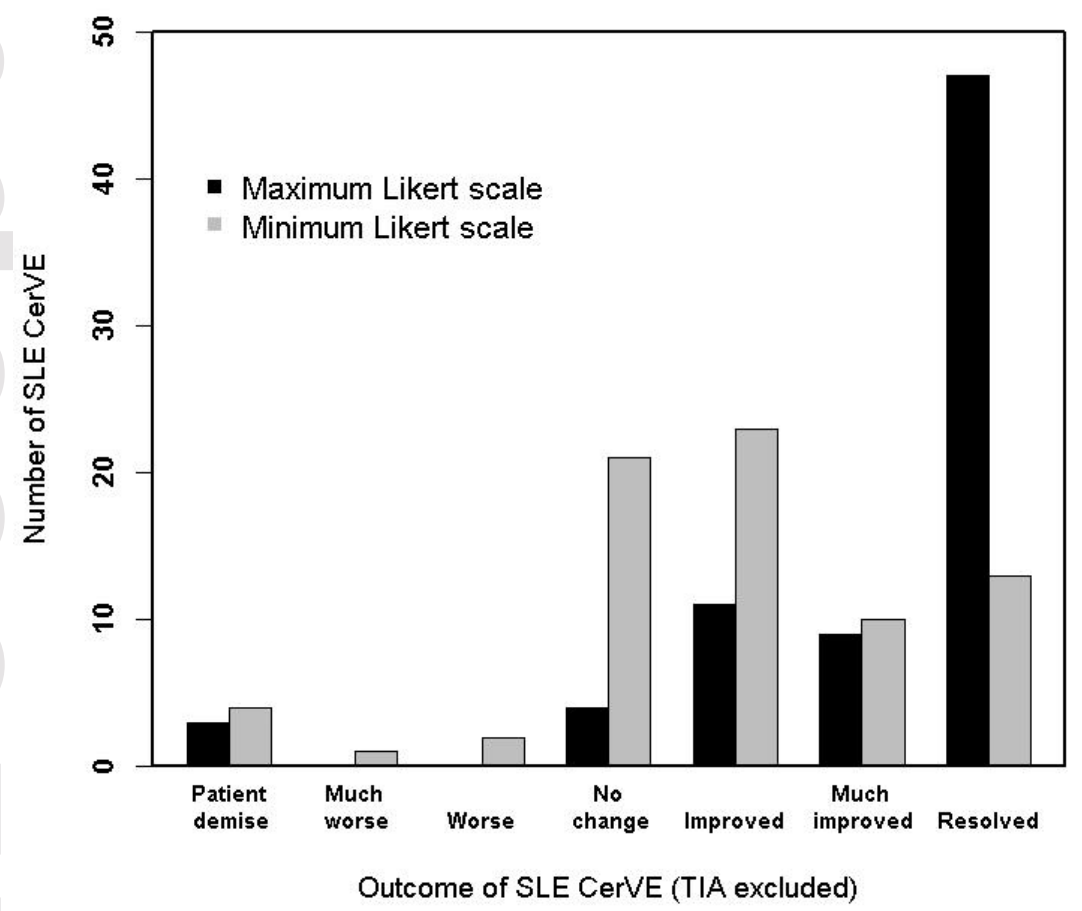

This article is protected by copyright. All rights reserved. 
Figure 3: Association of SF-36 summary and subscale scores with cerebrovascular events (CerVE) attributed to SLE using attribution model B.

A: mean (SD) physical component summary (PCS) and mental component summary (MCS) scores in the 3 patient groups. The number of assessments contributing to each bar are aggregated for patients over time. Thus one patient can contribute to both groups if her/his CerVE/NP status changed over time.

B: comparison individual subscale scores in the 3 patient groups. The SF-36 subscales are $\mathrm{VT}=$ Vitality, $\mathrm{SF}=$ Social function, $\mathrm{RE}=$ Role emotion, $\mathrm{MH}=$ Mental health, $\mathrm{PF}=$ Physical function, $\mathrm{RP}=$ Role physical, $\mathrm{BP}=$ Bodily pain, $\mathrm{GH}=$ General health .

A

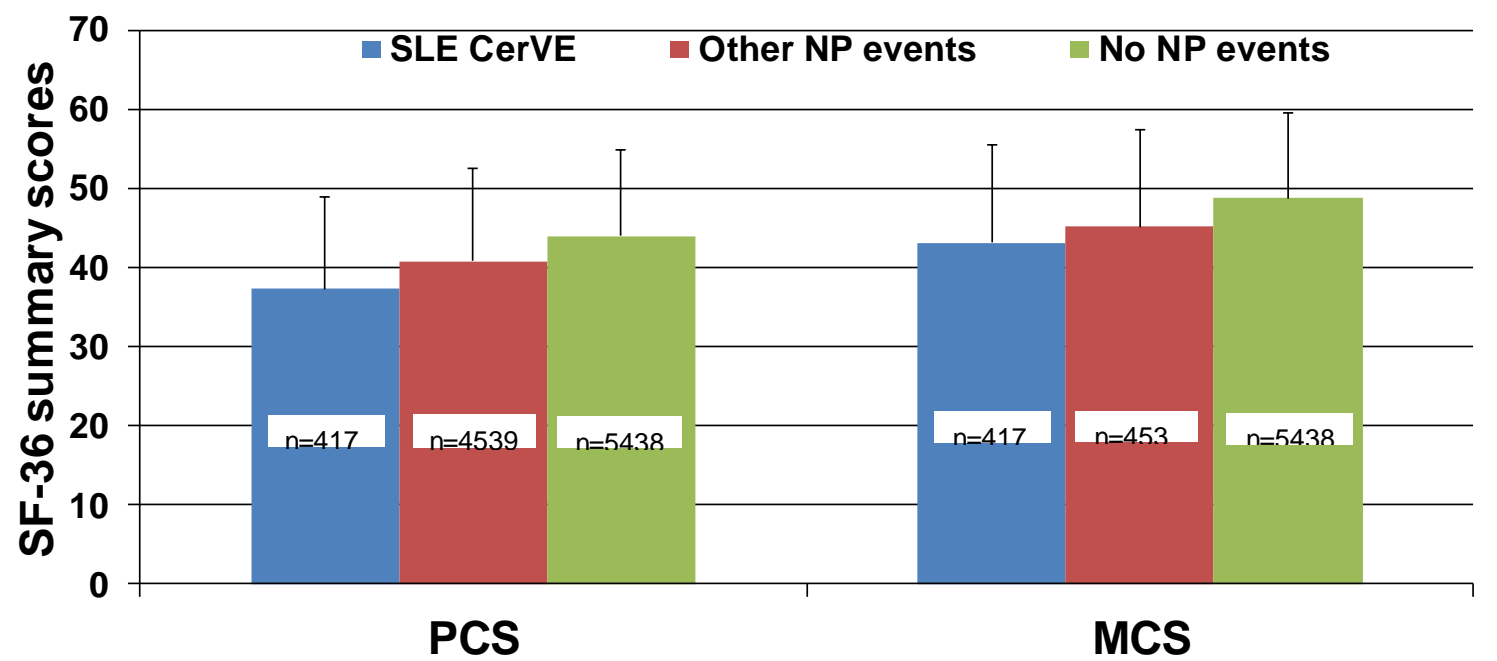

This article is protected by copyright. All rights reserved. 
B

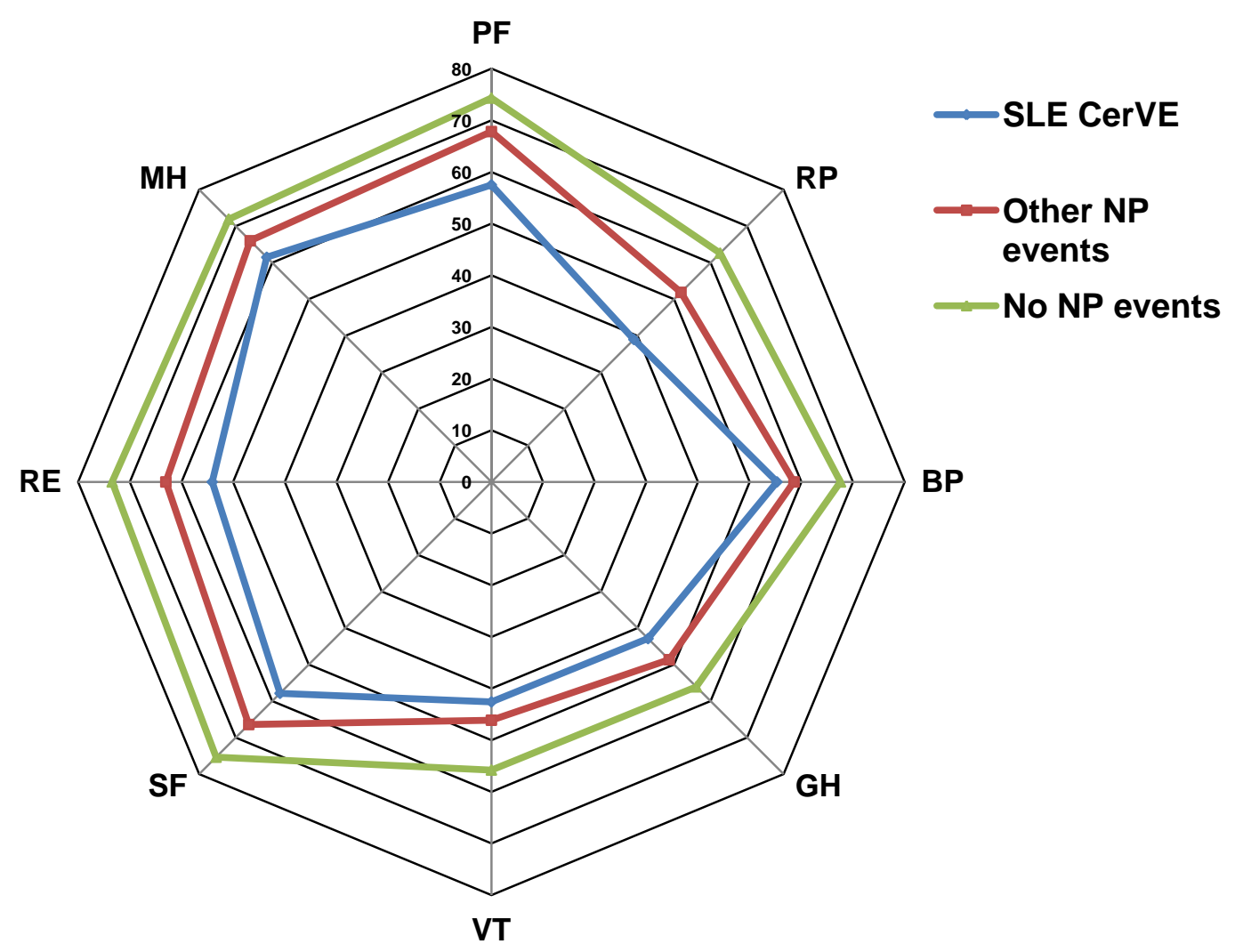

This article is protected by copyright. All rights reserved. 
Figure 4: SF-36 physical component summary (PCS) and mental component summary (MCS) scores with cerebrovascular events (CerVE) over time. Events were attributed to SLE using attribution model $B$.

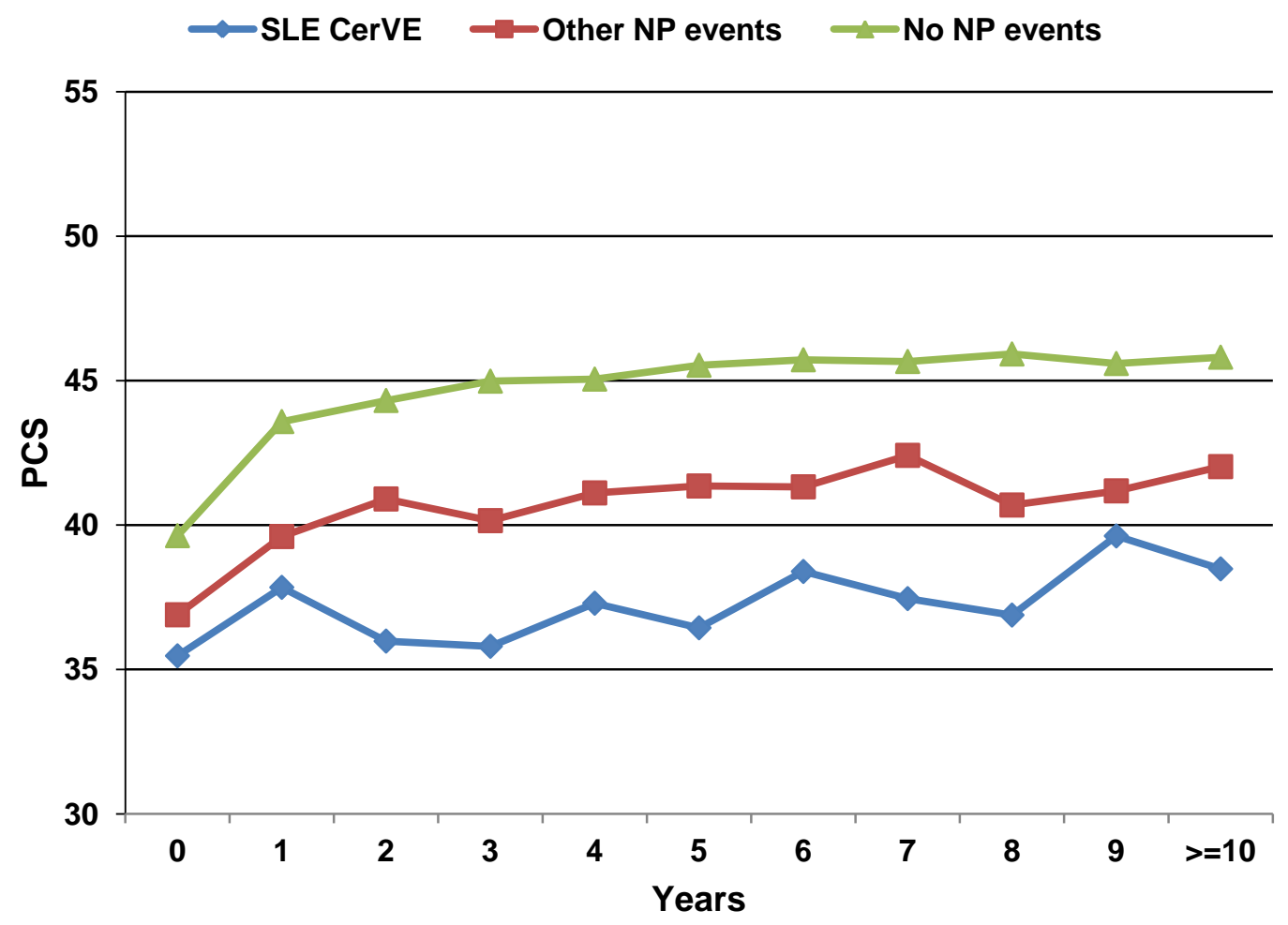

This article is protected by copyright. All rights reserved. 


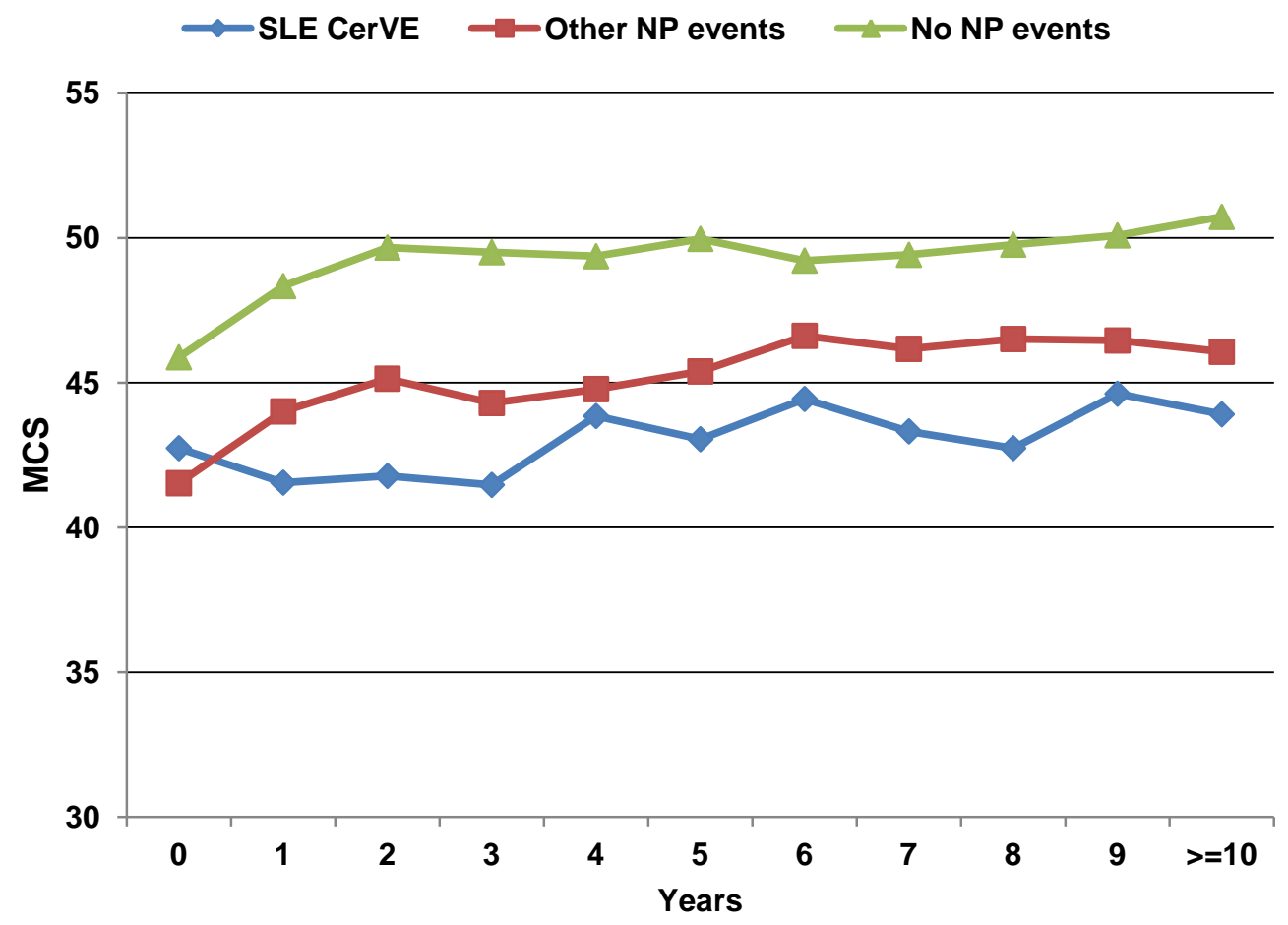

This article is protected by copyright. All rights reserved. 